\title{
The Class B Scavenger Receptor CD36 Mediates Free Radical Production and Tissue Injury in Cerebral Ischemia
}

\author{
Sunghee Cho, ${ }^{1}$ Eun-Mi Park, ${ }^{1}$ Maria Febbraio, ${ }^{2}$ Josef Anrather, ${ }^{1}$ Laibaik Park, ${ }^{1}$ Gianfranco Racchumi, ${ }^{1}$ \\ Roy L. Silverstein, ${ }^{2}$ and Costantino Iadecola ${ }^{1}$ \\ ${ }^{1}$ Division of Neurobiology, ${ }^{2}$ Department of Medicine/Hematology-Oncology, Weill Medical College of Cornell University, New York, New York 10021
}

\begin{abstract}
The class B scavenger receptor CD36 is involved in the cytotoxicity associated with inflammation, but its role in the inflammatory reaction that accompanies cerebral ischemia has not been examined. In this study, we investigated whether CD36 contributes to the brain damage produced by cerebral ischemia. The middle cerebral artery was transiently occluded in wild-type mice and in mice deficient in CD36. In wild-type mice, $\mathrm{CD} 36$ protein expression was increased in the ischemic brain, such that it was located predominantly in cells expressing the microglia/macrophage marker CD11b. The infarct produced by middle cerebral artery occlusion was $49 \%$ smaller in CD36-null mice than in wild-type controls, an effect associated with improved neurological function. The attenuation in brain injury in CD36 nulls could not be attributed to differences in cerebral blood flow during ischemia-reperfusion. However, the increase in reactive oxygen species (ROS) produced by cerebral ischemia was markedly attenuated in CD36-null mice in the early stage after reperfusion. The data unveil a previously unrecognized role of CD36 in ischemia-induced ROS production and brain injury. Modulation of CD36 signaling may provide a new strategy for the treatment of ischemic stroke.
\end{abstract}

Key words: CD36-null mice; stroke; inflammation; cerebral blood flow; hydroethidine; laser Doppler

\section{Introduction}

Cerebral ischemia initiates a cascade of cellular and molecular events that lead to brain damage (for review, see Lo et al., 2003). One such event is postischemic inflammation. Focal cerebral ischemia is associated with a local inflammatory reaction that contributes to the tissue damage (Iadecola et al., 2004). In particular, microglial cells become activated and provoke tissue injury by releasing proinflammatory mediators and reactive oxygen species (ROS) (Giulian, 1997; Schwartz, 2003). Blocking microglia activation by pharmacological interventions or genetic approaches ameliorates ischemic brain injury, attesting to the critical role that these cells play in the expression of the damage (Bruce et al., 1996; Yrjanheikki et al., 1999) (for review, see Schwartz, 2003). The mechanisms by which inflammatory cells contribute to this process are likely to involve ligand-mediated activation of surface receptors, but the identity of these receptors and theirs ligands remains to be defined (Giulian, 1997; Schwartz, 2003).

The class B scavenger receptor CD36 is a surface glycoprotein

Received Jan. 5, 2005; revised Jan. 25, 2005; accepted Jan. 25, 2005

This work was supported by American Heart Association Grant $0030225 \mathrm{~N}$ (S.C.) and National Institutes of Health (NIH) Grants R37-NS34179 (C.I.), R01-NS35806 (C.I.), and 1P01-HL46403 (R.L.S., M.F.). C.I. is the recipient of a Javits Award from NIH-National Institute of Neurological Disorders and Stroke.

Correspondence should be addressed to Dr. Costantino ladecola, Division of Neurobiology, Weill Medical College of Cornell University, 411 East 69th Street, KB410, New York, NY 10021. E-mail: coi2001@med.cornell.edu.

S. Cho's present address: Burke Medical Research Institute, 785 Mamaroneck Avenue, White Plains, NY 10605.

E.-M. Park's present address: Department of Pharmacology, College of Medicine, Ewha Womans University, 911-1, Mok-6-Dong, Yangcheon-Gu, Seoul, Republic of Korea, 158-710.

M. Febbraio and R. L. Silverstein's present address: Department of Cell Biology, NC10, Lerner Research Institute, The Cleveland Clinic Foundation, 9500 Euclid Avenue, Cleveland, OH 44195

DOI:10.1523/JNEUROSCI.0035-05.2005

Copyright $\odot 2005$ Society for Neuroscience $\quad$ 0270-6474/05/252504-09\$15.00/0 found in microglia, macrophages, microvascular endothelium, cardiac and skeletal muscle, adipocytes, and platelets (Febbraio et al., 2001). CD36 recognizes a multitude of ligands, including oxidized low-density lipoprotein (LDL), long-chain fatty acids, thrombospondin-1, fibrillar $\beta$-amyloid $(\mathrm{A} \beta)$, and the membrane of cells undergoing apoptosis (Febbraio et al., 2001; Hirano et al., 2003; Medeiros et al., 2004). CD36 has been implicated in a wide variety of normal and abnormal biological functions, including angiogenesis, atherosclerosis, phagocytosis, inflammation, lipid metabolism, and removal of apoptotic cells (Febbraio et al., 2001; Hirano et al., 2003).

A growing body of evidence indicates that CD36 is also involved in the cytotoxicity associated with inflammation (Febbraio et al., 2001; Hirano et al., 2003). CD36 may be an essential mediator of the production of inflammatory mediators and ROS induced by fibrillar $\mathrm{A} \beta$ in microglial cell cultures (Coraci et al., 2002; Moore et al., 2002; El Khoury et al., 2003). However, it has not been established whether CD36 contributes to injury in brain diseases associated with inflammation (Husemann et al., 2002). Cerebral ischemia produces several CD36 ligands, including long-chain fatty acids, $A \beta$, oxidized LDL, and thrombospondin-1 (Nihashi et al., 2001; Hayashi et al., 2003; Pilitsis et al., 2003; Uno et al., 2003; Shie et al., 2004). It is therefore conceivable that this receptor participates in the inflammatory response associated with brain ischemia and contributes to its deleterious effects.

In this study, we used a mouse model of cerebral ischemia-reperfusion to determine whether CD36 participates in ischemic brain injury. We found that CD36 is upregulated after ischemia-reperfusion primarily in microglia/macrophage cells. Furthermore, mice lacking the CD36 receptor have a profound reduction in ROS production after ischemia and are relatively protected from ischemic 
injury. These findings identify CD36-mediated ROS production as a new mechanism of ischemic brain damage, and raise the possibility that $\mathrm{CD} 36$ could be a therapeutic target in human stroke.

\section{Materials and Methods}

All of the experimental procedures were approved by the Institutional Animal Care and Use Committee.

Animals. Experiments were performed in male CD36-null mice and wild-type controls weighing 20-22 g. Mice were backcrossed six times into the C57BL/6J strain and housed at Weill Medical College of Cornell University. Procedures for breeding and genotyping CD36-null mice were described previously (Febbraio et al., 1999).

Transient middle cerebral artery occlusion. Procedures for middle cerebral artery (MCA) occlusion are identical to those previously described (Nogawa et al., 1997; Park et al., 2004) and are only summarized. Mice were anesthetized with a mixture of isoflurane (1.5-2\%), oxygen, and nitrogen. A fiber optic probe was glued to the parietal bone $(2 \mathrm{~mm}$ posterior and $5 \mathrm{~mm}$ lateral to bregma) and connected to a laser-Doppler flowmeter (Periflux System 5010; Perimed, Järfälla, Sweden) for continuous monitoring of cerebral blood flow $(\mathrm{CBF})$ in the center of the ischemic territory. In some experiments, one additional probe was placed 2 $\mathrm{mm}$ lateral to bregma for $\mathrm{CBF}$ monitoring at the periphery of the ischemic territory (Iadecola et al., 1999a). For MCA occlusion, a heatblunted black monofilament surgical suture (6-0) was inserted into the exposed external carotid artery, advanced into the internal carotid artery, and wedged into the circle of Willis to obstruct the origin of the MCA. The filament was left in place for $20 \mathrm{~min}$ and then withdrawn. Only animals that exhibited a reduction in $\mathrm{CBF}>85 \%$ during MCA occlusion and in which CBF recovered by $>80 \%$ after $10 \mathrm{~min}$ of reperfusion were included in the study. This procedure leads to reproducible infarcts involving both the cerebral cortex and the striatum (see Fig. $1 B$ ). Rectal temperature was kept at $37.0 \pm 0.5^{\circ} \mathrm{C}$ during surgery and in the recovery period until animals regained consciousness.

Infarct volume measurement and assessment of functional deficits. Mice were killed $3 \mathrm{~d}$ after ischemia. Brains were removed, frozen, and sectioned (thickness, $30 \mu \mathrm{m}$ ) in a cryostat as previously described (Iadecola et al., 1999a; Iadecola et al., 2001). Brain sections were collected serially at $600 \mu \mathrm{m}$ intervals, and stained by the Nissl method. Infarct volume was determined using an image analyzer (MCID; Imaging Research, St. Catharines, Ontario, Canada). To eliminate the contribution of postischemic edema to the volume of injury, infarct volume measurements were corrected for swelling according to the method of Lin et al. (1993). The functional deficits produced by the stroke were graded using the "hanging-wire test" (Ikegami et al., 2000; Freitag et al., 2003), performed $3 \mathrm{~d}$ after ischemia. Animals were made to grasp with the forepaws a thin wire suspended above ground, and the latency to fall was recorded. The test was repeated three times for each animal with a 5 min rest between trials, and the scores from three trials were averaged.

Western blot analysis. The forebrain was sectioned in half, and each hemisphere was frozen in liquid nitrogen and homogenized in $2 \mathrm{ml}$ of radioimmunoprecipitation assay (RIPA) buffer $(50 \mathrm{~mm}$ Tris $\cdot \mathrm{Cl}, \mathrm{pH} 8.0$, $150 \mathrm{~mm} \mathrm{NaCl}, 5 \mathrm{~mm} \mathrm{NaF}, 0.5 \%$ sodium deoxycholate, $0.1 \%$ SDS, $1 \mathrm{~mm}$ EDTA, $1 \%$ Nonidet P-40) with freshly added protease inhibitor [a Complete Mini Protease Inhibitor Tablet (Roche Applied Science, Indianapolis, IN)/10 $\mathrm{ml}$ of RIPA buffer]. The homogenate was centrifuged at $13,000 \mathrm{rpm}$ for $10 \mathrm{~min}$ at $4^{\circ} \mathrm{C}$, and the protein concentration of the supernatant was determined using the Bradford method (Bio-Rad, Hercules, CA). Thirty micrograms of protein were loaded on a gel. Electrophoresis was performed, and proteins were transferred from the gel to polyvinylidene difluoride filters using an electroblotting apparatus. Filters were treated for $1 \mathrm{~h}$ in TBS ( $\mathrm{pH} 7.2$ ) containing $0.1 \%$ Tween 20 and $5 \%$ dry milk, and then incubated with an anti-murine CD36 monoclonal antibody developed in our laboratory (Finnemann and Silverstein, 2001) (dilution, 1:1000; MAB1258; Chemicon, Temecula, CA), followed by anti-mouse IgA-HRP (Sigma, St. Louis, MO). Filters were washed, and the bands were visualized using a chemiluminescence detection system (Santa Cruz Biotechnology, Santa Cruz, CA).

Immunocytochemistry. Six hours, $1 \mathrm{~d}$, and $3 \mathrm{~d}$ after ischemia, mice $(n=$ 3/group) were anesthetized with sodium pentobarbital $(120 \mathrm{mg} / \mathrm{kg})$ and perfused transcardially with $5 \mathrm{ml}$ of heparin sulfate $(1000 \mathrm{U} / \mathrm{ml})$ followed by $50 \mathrm{ml}$ of histochoice tissue fixative MB (Amresco, Solon, OH). Shamoperated mice served as controls ( $n=2$ /group). The brains were postfixed overnight and transferred to a $30 \%$ sucrose solution. The following day, brains were sectioned coronally in a cryostat (thickness, $20 \mu \mathrm{m}$ ). For CD36 immunolabeling, sections were incubated overnight with a polyclonal CD36 antibody (1:300; Santa Cruz Biotechnology). Sections were then sequentially incubated with biotinylated anti-rabbit secondary antibody for $1 \mathrm{~h}$ and fluorescein-avidin $\mathrm{D}$ for $1 \mathrm{~h}$. To identify the cell type(s) that express CD36, CD36-immunolabeled sections were incubated with antibodies against the microglia/macrophage marker CD11b, the astroglial marker glial fibrillary acidic protein (GFAP), or the neuronal marker class III $\beta$-tubulin (TUJ1). Sections were then incubated with biotinylated secondary anti-rat (CD11b) or anti-rabbit (GFAP and TUJ1) antibody followed by Texas Red-avidin D. The specificity of the CD36 immunolabel was tested by omitting the primary antibody and by processing brain sections of CD36-null mice $(n=2)$.

Cerebrovascular reactivity. As described in detail previously (Iadecola et al., 1999b; Niwa et al., 2000, 2001), mice were anesthetized with isoflurane (1-2\%), and the left femoral artery was cannulated for monitoring of mean arterial pressure (MAP). Mice were artificially ventilated with an oxygen-nitrogen mixture adjusted to obtain $\mathrm{pO}_{2}$ of $120-140 \mathrm{mmHg}$. End-tidal $\mathrm{CO}_{2}$, monitored by a $\mathrm{CO}_{2}$ analyzer (Capstar-100; CWE, Ardmore, PA), was maintained at $2.6-2.7 \%$. Isoflurane was then discontinued, and anesthesia was maintained with urethane $(750 \mathrm{mg} / \mathrm{kg}$, i.p.) and $\alpha$-chloralose (50 mg/kg, i.p.). The somatosensory cortex was exposed via a $2 \times 2 \mathrm{~mm}$ cranial window, and the dura was removed. The site was superfused with a modified Ringer's solution $\left(37^{\circ} \mathrm{C}\right.$; $\left.\mathrm{pH} 7.3-7.4\right)$ (for composition, see Iadecola, 1992), and CBF was continuously monitored at the site of superfusion with a laser-Doppler probe (Vasamedic, St. Paul, MN). Throughout the experiment, body temperature was kept at $37.5 \pm 0.5^{\circ} \mathrm{C}$ by a heating pad thermostatically regulated by a rectal probe. To study the increase in CBF produced by neural activity, the somatosensory cortex was activated by gently stroking the contralateral facial whiskers with a cotton-tipped applicator at a frequency of 3-4 Hz. To study endothelium-dependent vasodilation, the increase in CBF induced by superfusion of the window with acetylcholine (10 $\mu \mathrm{M}$; Sigma) was monitored (Iadecola et al., 1999b; Niwa et al., 2000, 2001). The increase in $\mathrm{CBF}$ produced by hypercapnia was studied by introducing $\mathrm{CO}_{2}$ in the circuit of the ventilator to increase arterial $\mathrm{pCO}_{2}$ up to $50-60$ $\mathrm{mmHg}$ (Iadecola et al., 1999b; Niwa et al., 2000, 2001). To test the CBF response to hypotension, MAP was slowly lowered from 100 to $20 \mathrm{mmHg}$ in $10 \mathrm{mmHg}$ steps by removal of small amounts of arterial blood (100$200 \mu \mathrm{l}$ ), as described previously (Niwa et al., 2002). CBF values were recorded 5 min after a stable level of MAP was reached. CBF values were expressed as percentage change relative to the resting level. Zero values for $\mathrm{CBF}$ were obtained after the heart was stopped by an overdose of isoflurane at the end of the experiment.

Determination of ROS production. ROS production was assessed using in vivo hydroethidine fluoromicrography (Kondo et al., 1997; Murakami et al., 1998), as previously described (Manabe et al., 2004). Hydroethidine, a cell-permeable oxidative fluorescent dye, is oxidized to ethidium by superoxide (Carter et al., 1994; Bindokas et al., 1996). Ethidium, which exhibits peak absorbance at $520 \mathrm{~nm}$ and an emission maximum at $600 \mathrm{~nm}$, is trapped intracellularly by intercalating with DNA (Rothe and Valet, 1990). The fluorescence signal attributable to ethidium reflects cumulative ROS production during the period between administration of hydroethidine and killing of the animal. Hydroethidine $(10 \mathrm{mg} / \mathrm{kg})$ was injected into the jugular vein of isoflurane-anesthetized mice and allowed to circulate for $4 \mathrm{~h}$. Mice were killed, and brains were removed and frozen. Serial sections (thickness, $20 \mu \mathrm{m}$ ) were cut in a cryostat, collected at $600 \mu \mathrm{m}$ intervals, and viewed with a Nikon (Melville, NY) E800 fluorescence microscope equipped with an ethidium filter set (no. 31014; Chroma Technology, Rockingham, VT). Images were acquired by a computer-controlled digital monochrome camera (Coolsnap; Roper Scientific, Trenton, NJ) attached to the microscope. The analysis of ROS production was performed in a blinded manner using the IPLab software package (Scanalytics, Fairfax, VA) (Manabe et al., 2004). After subtrac- 

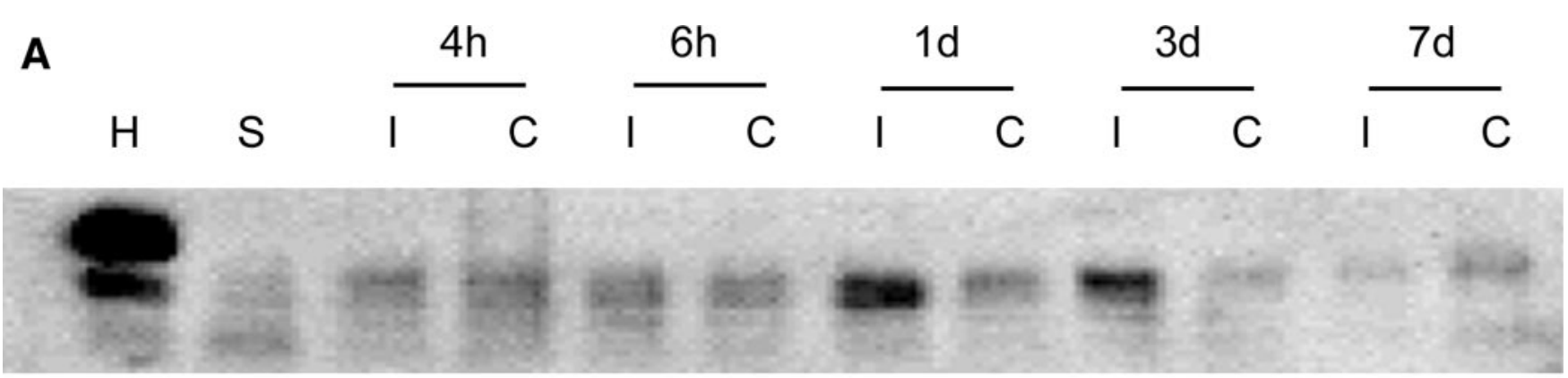

\section{B}
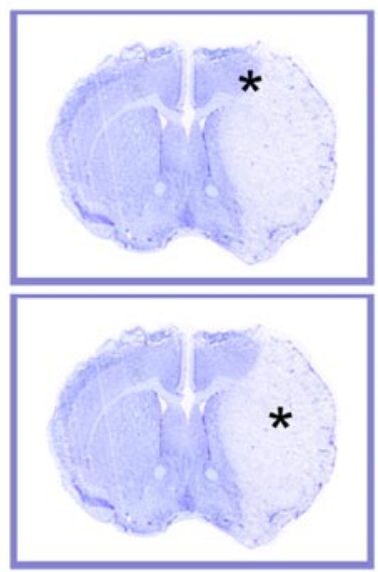
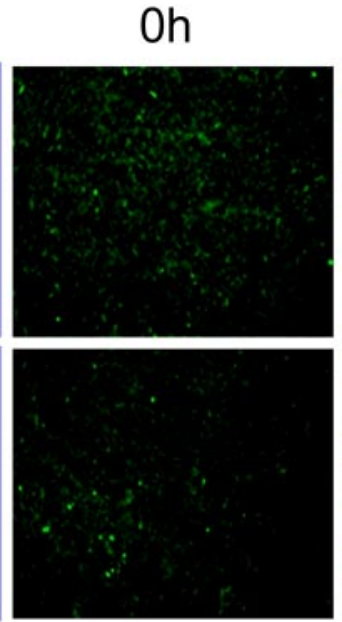
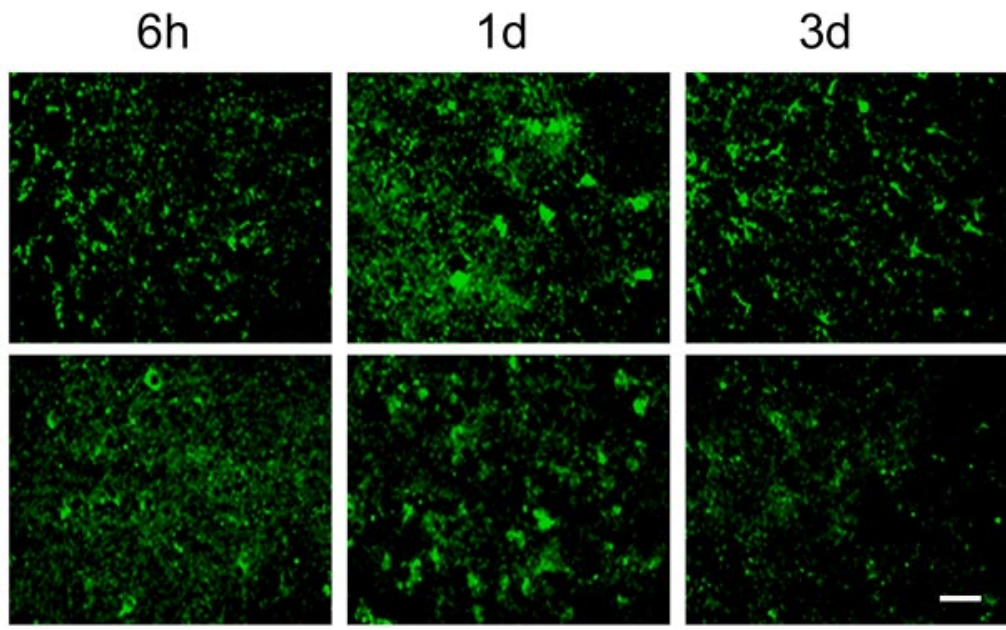

Figure 1. CD36 expression in the postischemic brain. $\boldsymbol{A}$, Representative time course of postischemic CD36 expression by Western blot. H, Heart (positive control); S, sham; I, ipsilateral; C, contralateral. $\boldsymbol{B}$, The Nissl-stained brain sections on the left show the distribution of the damage $3 \mathrm{~d}$ after MCA occlusion. The asterisks indicate the sampling sites at the center and periphery of the infarct. The fluorescence micrographs illustrate the time course of CD36 immunoreactivity at the border (top) and at the center of the infarct (bottom). "0h" indicates sham-operated mice. Scale bar, $10 \mu \mathrm{m}$.

tion of the camera dark current, pixel intensities of ethidium signals were assessed in predefined areas of the ischemic cortex and striatum. Fluorescence intensity was measured in five serial sections per animal (rostrocaudal levels, $+1.6,+1.0,+0.4,-0.2,-0.8 \mathrm{~mm}$ from bregma). The sum of the fluorescence intensity for each region was divided by the total number of pixels analyzed and expressed as relative fluorescence units (Manabe et al., 2004).

Statistical analysis. Data are presented as mean \pm SEM. Comparisons between two groups were statistically evaluated by Student's $t$ test. Multiple comparisons were evaluated by ANOVA and Fisher's PLSD test. Differences were considered significant at $p<0.05$.

\section{Results}

CD36 expression is increased in the postischemic brain

We first examined the expression of CD36 in the postischemic brain. Western blot analysis showed low levels of CD36 expression in sham-operated mice (Fig. $1 A$ ). After ischemia, the CD36 band was slightly increased at $6 \mathrm{~h}$, peaked at 1-3 d, and returned to baseline at $7 \mathrm{~d}$ (Fig. $1 A$ ). We then used immunocytochemistry to define the cell type expressing CD36. In sham-operated mice, CD36 immunoreactivity was observed in endothelial cells, consistent with previous reports (Coraci et al., 2002). After cerebral ischemia, the number of CD36-immunoreactive cells increased both at the center and periphery of the infarct (Fig. $1 B$ ). The increase was observed at $6 \mathrm{~h}$ and persisted at $3 \mathrm{~d}$ after ischemia (Fig. $1 B$ ). In the center of the lesion, CD36 immunoreactivity was present in cells that were also positive for the macrophage/microglia marker CD11b (Fig. 2A). We could not determine whether CD36 was expressed in infiltrating neutrophils. At the periphery of the infarct, CD36 immunoreactivity was observed in cells also positive for the astroglial marker GFAP, but only at $3 \mathrm{~d}$ after ischemia (Fig. 2 B). However, CD36 immunoreactivity was rarely seen in cells positive for the neuronal marker TUJ1 (data not shown). CD36 immunoreactivity in regions contralateral to the infarct was similar to that observed in sham-operated mice. Furthermore, no immunoreactivity was observed in CD36-null mice.

\section{Ischemic brain injury and motor deficits are reduced in CD36 nulls}

To establish whether CD36 contributes to ischemic brain injury, the MCA was transiently occluded in CD36-null mice and wildtype controls, and infarct volume was assessed $3 \mathrm{~d}$ later. In wildtype mice, ischemia produced a well defined infarct involving both the neocortex and the striatum (Figs. $1 B, 3$ ). CD36-null mice exhibited an infarct $49 \%$ smaller than that of wild-type mice (Fig. $3 A, B$ ). The reduction in infarct volume was associated with a better performance on the hanging-wire test (Fig. 3C).

\section{Postischemic hyperemia is attenuated in CD36-null mice}

To determine whether the reduction in infarct size in CD36-null mice was related to a hemodynamic factors leading to a milder ischemic insult, we monitored CBF during ischemia and reperfusion. As anticipated, MCA occlusion reduced CBF more in the center than in the periphery of the ischemic territory (Fig. 4). The $\mathrm{CBF}$ reductions did not differ between wild-type and CD36-null mice $(p>0.05)$ (Fig. 4). In wild-type mice, during reperfusion, 
A

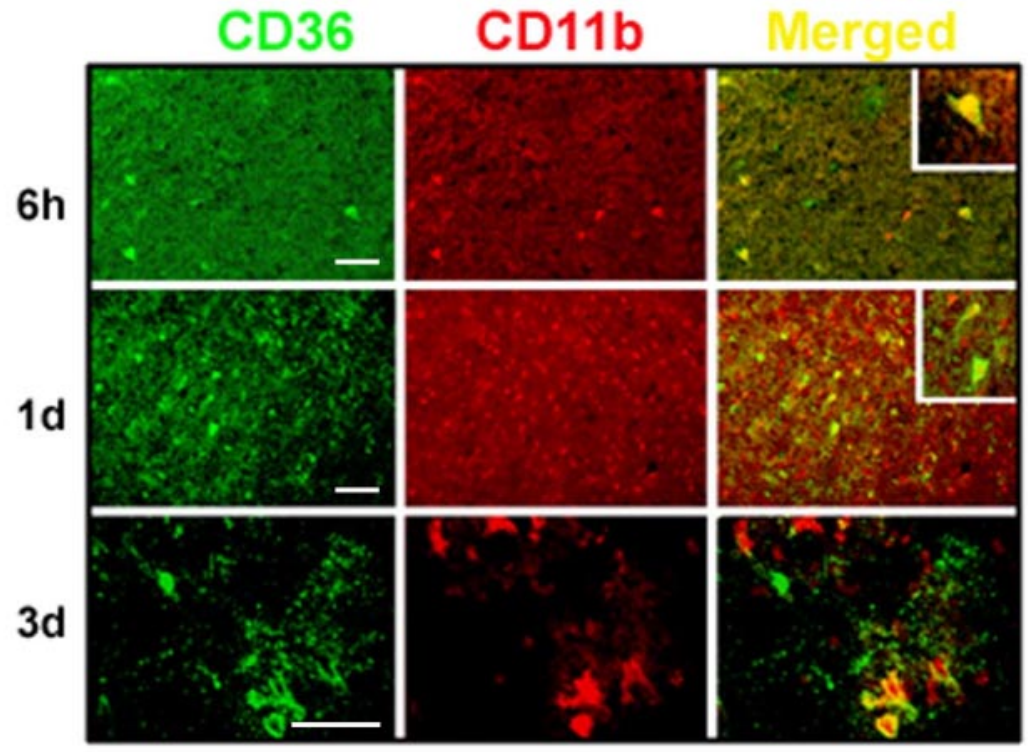

B

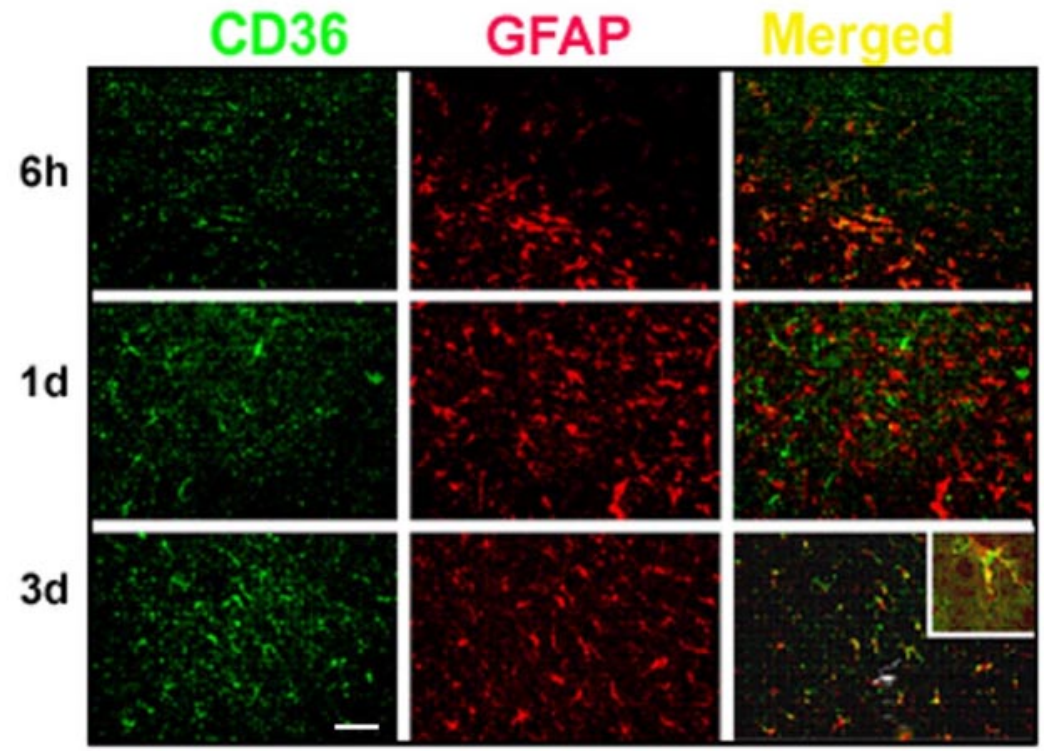

Figure 2. Cell types expressing CD36 in the infarct at different time points after ischemia. $\boldsymbol{A}, \mathrm{CD} 36$ immunoreactivity (green) and the microglial/macrophage marker CD11b (red) are colocalized (yellow in the merged image) in cells at the center of the infarct. $B$, CD36 immunoreactivity (green) and the astrocytic marker GFAP (red) are colocalized (yellow) in cells at the periphery of the infarct, but only at $3 \mathrm{~d}$ after ischemia. Insets in $\boldsymbol{A}$ and $\boldsymbol{B}$ illustrate positive cells at higher magnification. Scale bar, $10 \mu \mathrm{m}$.

CBF in the ischemic core increased above preischemic levels (postischemic hyperemia or hyperperfusion) and then decreased below preischemic levels (postischemic hypoperfusion) (Fig. 4A) (Iadecola, 1998). At the periphery of the ischemic territory, CBF at reperfusion increased up to preischemic levels and then decreased into postischemic hypoperfusion (Fig. $4 B$ ). In CD36 nulls, the increase in $\mathrm{CBF}$ at reperfusion was markedly attenuated both in the center and periphery of the ischemic territory (Fig. 4). However, postischemic hypoperfusion did not differ between wild-type mice and CD36 nulls (Fig. 4). MAP, measured before ischemia and $10 \mathrm{~min}$ after, was comparable in wild-type and CD36-null mice (preischemia: wild type, $73 \pm 3 \mathrm{mmHg}$; CD36 nulls, $74 \pm 2 \mathrm{mmHg}$; postischemia: wild type, $72 \pm 5 \mathrm{mmHg}$; CD36 nulls, $75 \pm 2 \mathrm{mmHg}$; $n=6$ /group).

The attenuation in $\mathrm{CBF}$ at reperfusion raised the possibility that the reactivity of the cerebral circulation was diminished in CD36-null mice, resulting in a reduced response to the vasoactive factors released at reperfusion (Iadecola, 1998). To address these issues, we examined selected vasodilatatory responses of the cerebral circulation in CD36 nulls. As illustrated in Figure $5 A$, the increase in CBF produced by functional hyperemia (whisker stimulation), by hypercapnia, and by the endothelium-dependent vasodilator acetylcholine did not differ between wild-type mice and CD36 nulls. Similarly, the ability to maintain CBF during hypotension, a response mediated by vasodilation of resistance arterioles (Paulson et al., 1990), was not different between the two groups of mice (Fig. $5 B$ ). Thus, a reduced reactivity to vasodilatatory stimuli is unlikely to contribute to the attenuated postischemic hyperemia observed in CD36-null mice.

\section{ROS production is attenuated in} CD36-null mice

ROS play a major pathogenic role in the mechanisms of ischemic brain injury (Chan, 2001). Because CD36 signaling is linked to ROS production (Coraci et al., 2002; El Khoury et al., 2003), we used the hydroethidine technique to study the role of CD36 in postischemic ROS production. In wild-type mice, the ROS signal increased in the injured cortex and striatum during the first $4 \mathrm{~h}$ of reperfusion (Fig. 6). A second rise was observed in the cortex between 20 and $24 \mathrm{~h}$ (Fig. 6 B, C). In CD36null mice, ROS production was profoundly attenuated in cortex and striatum during the first $4 \mathrm{~h}$ of reperfusion (Fig. 7). However, no difference in ROS production between wild-type mice and CD36 nulls was observed at 20-24 h (Fig. 7B).

\section{Discussion}

We sought to define the role of the scavenger receptor CD36 in cerebral ischemic injury. We found that CD36 is upregulated in the ischemic territory primarily in microglia/macrophages. To assess the pathogenic significance of such upregulation, we investigated mice lacking CD36 (Febbraio et al., 1999). We found that CD36 nulls have smaller infarcts and milder functional deficits after focal cerebral ischemia. To determine whether the protection was a consequence of hemodynamic factors resulting in a reduced level of ischemia, $\mathrm{CBF}$ was measured during ischemia and reperfusion. We found that the degree of $\mathrm{CBF}$ reduction produced by MCA occlusion in the center and periphery of the ischemic territory did not differ between wild-type mice and CD36 nulls, but that the CBF increase occurring at reperfusion was less pronounced in CD36 nulls. Furthermore, the protection in CD36 nulls was associated with a marked reduction in postischemic ROS production during the early phase of reperfusion. These findings, collectively, provide evidence that CD36 is a novel factor involved in the mechanisms of ischemic brain injury.

The reduction in ischemic damage in CD36 nulls cannot be 


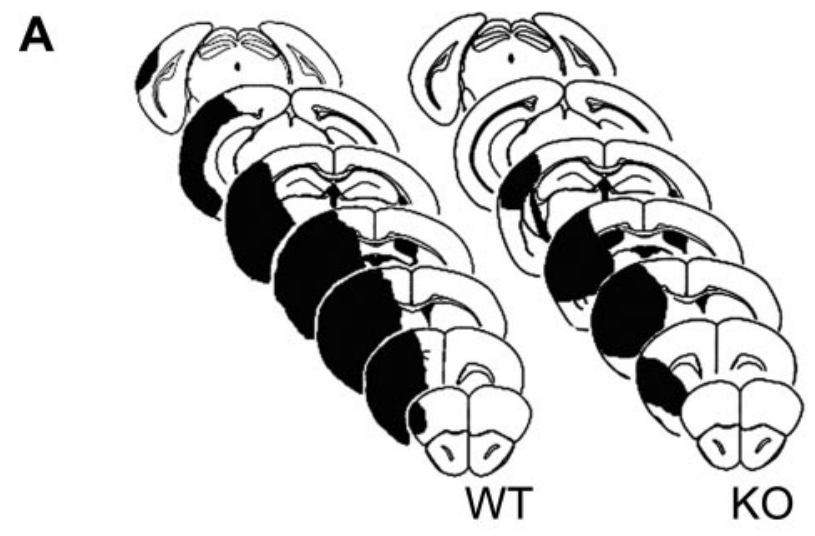

B

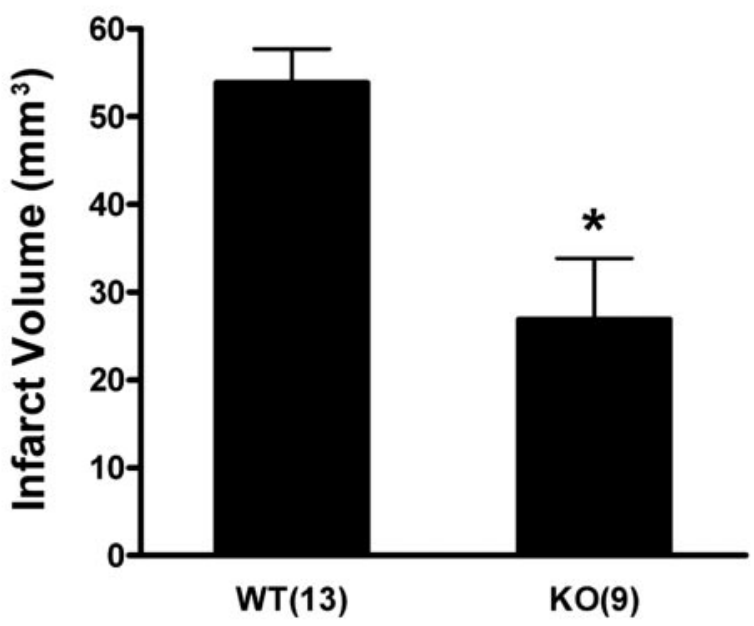

C

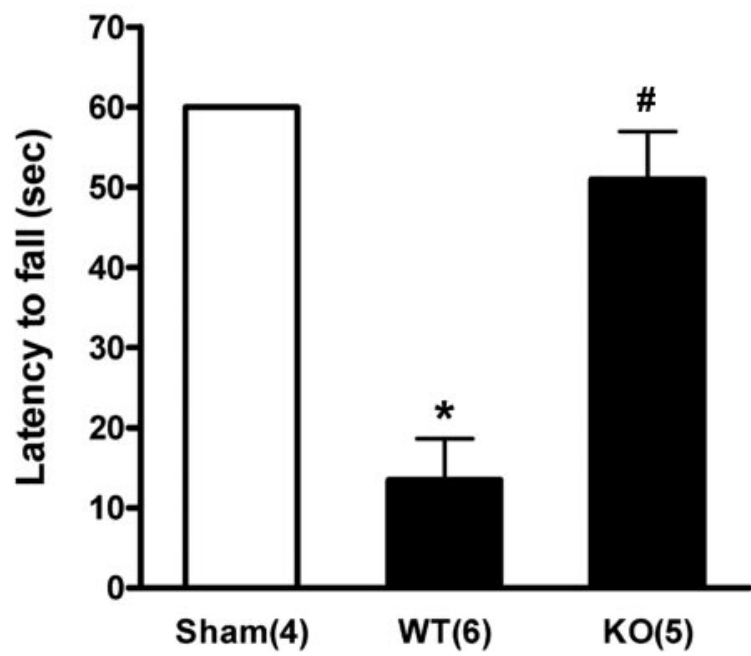

Figure 3. Infarct size and functional deficits in wild-type (WT) and CD36-null (KO) mice subjected to MCA occlusion. $A$, Rostrocaudal distribution of the infarct in WT and KO. B, Reduction in infarct volume in K0 $3 \mathrm{~d}$ after ischemia. ${ }^{*} p<0.05$, Student's $t$ test. Error bars indicate SE. C, Performance on the hanging-wire test $3 \mathrm{~d}$ after ischemia. Scores indicate the latency to fall in seconds. Error bars indicate SE. ${ }^{*} p<0.05$ from sham, ${ }^{\#} p<0.05$ versus WT, one-way ANOVA with post hoc Fisher's PLSD test.

attributed to differences in the genetic background of the mice, because we used littermates as controls. Furthermore, the mice were backcrossed for generations, thereby minimizing further the influence of the background strain on the outcome of cerebral ischemia (Choi, 1997). In addition, CD36-null and wild-type
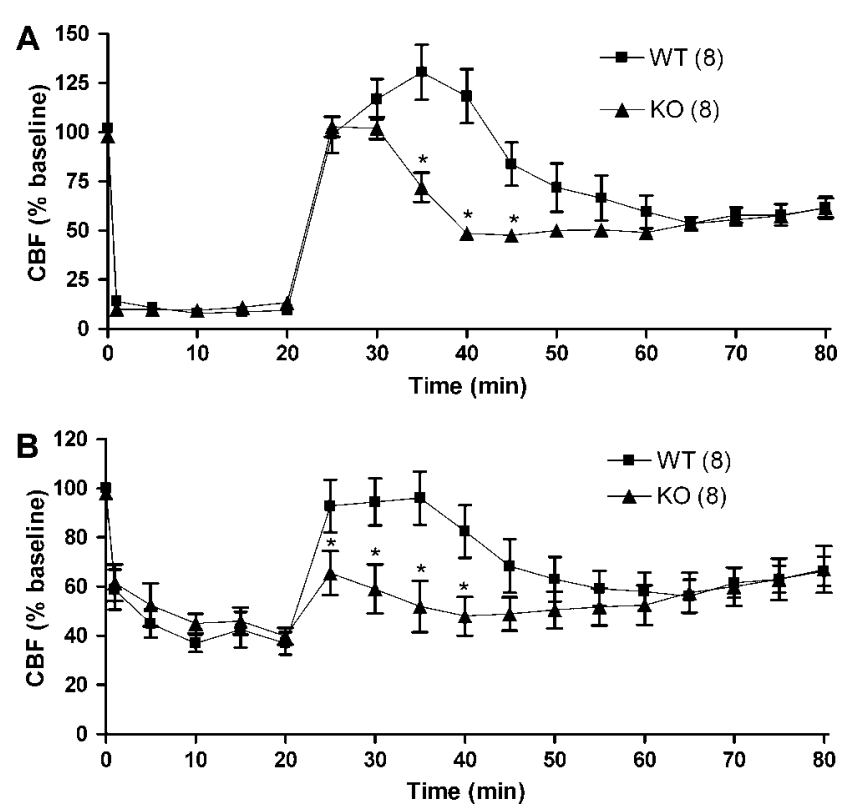

Figure 4. Time course of postischemic CBF in wild-type (WT) and CD36-null (KO) mice. CBF was continuously monitored before and after ischemia-reperfusion in the center $(\boldsymbol{A})$ and periphery $(\boldsymbol{B})$ of the ischemic territory. Error bars indicate SE. ${ }^{*} p<0.05$ between WT and K0 at that time point, Student's $t$ test.
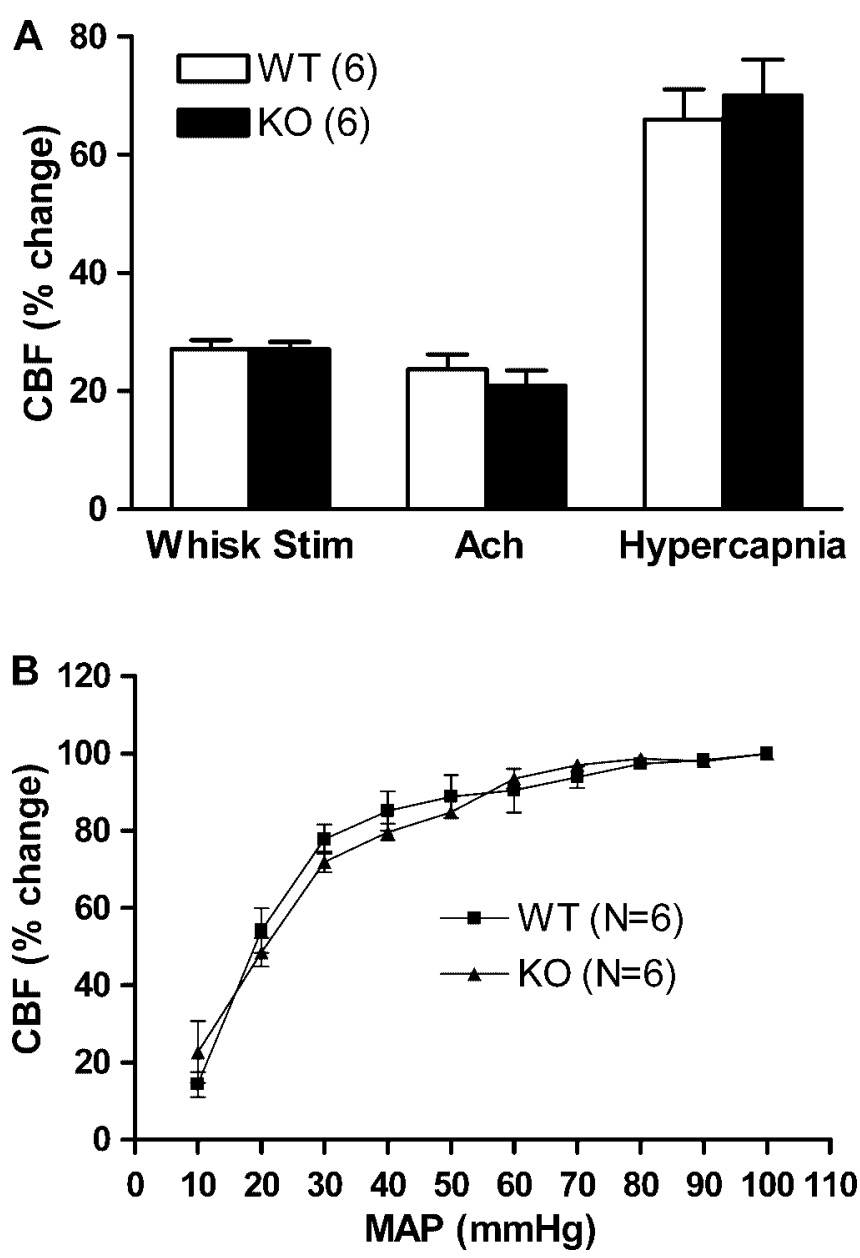

Figure 5. Assessment of cerebrovascular function in wild-type (WT) and CD36-null (KO) mice. $A$, Increases in somatosensory cortex CBF produced by whisker stimulation (Whisk Stim), acetylcholine (Ach) $(10 \mu \mathrm{m})$, and hypercapnia (arterial p $\left.\mathrm{CO}_{2}, 50-60 \mathrm{mmHg}\right) . B$, CBF changes induced by graded hypotension. Error bars indicate SE. 
A

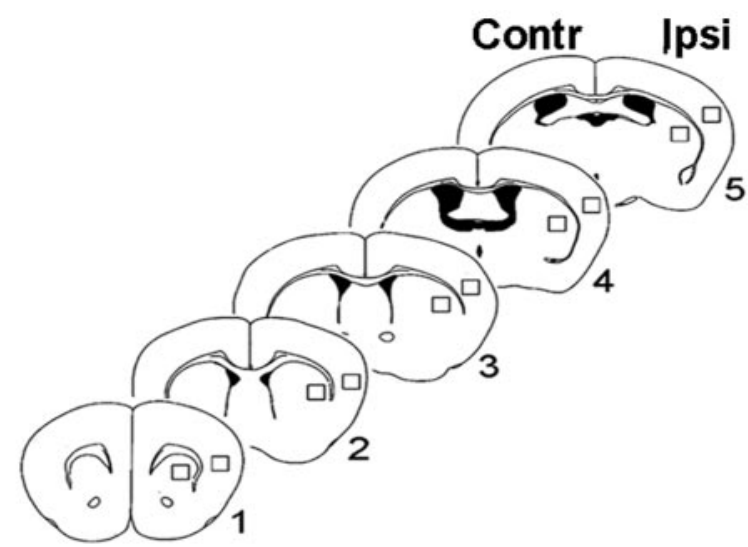

B

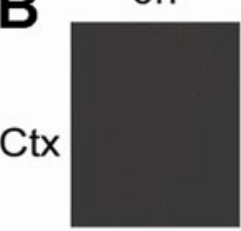

$1 \mathrm{~h}$
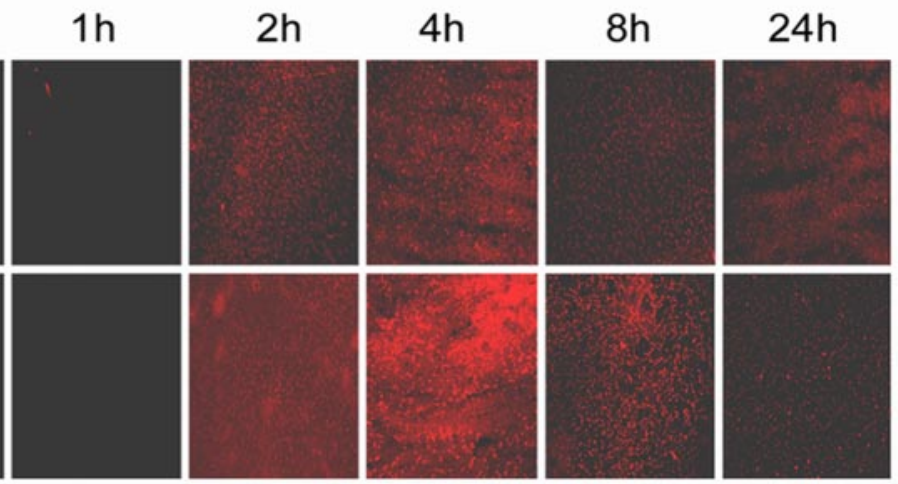

C
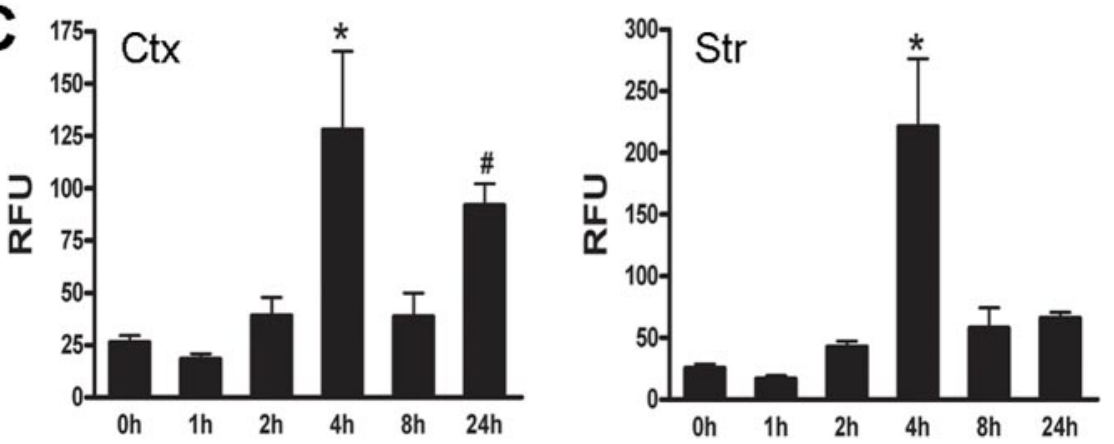

Figure 6. Temporal profile of ROS production in the postischemic brain assessed by hydroethidine microfluorography in wild-type mice. $\boldsymbol{A}$, Regions of the cortex and striatum from which the ROS signal was measured (see Materials and Methods for coordinates). Contr, Contralateral; Ipsi, ipsilateral. $\boldsymbol{B}, \mathrm{ROS}$ signal in cortex (Ctx) and striatum (Str) in sham-operated controls ( $0 \mathrm{~h}$ ), and $1,2,4,8$, and $24 \mathrm{~h}$ after ischemia. $\boldsymbol{C}$, Semiquantitative analysis of the time course of ROS production in cortex (left) and striatum (right). Error bars indicate SE. ${ }^{*} p<0.01$ from $0 \mathrm{~h}$; ${ }^{\#} p<0.04$ from $0 \mathrm{~h}$ (ANOVA with post hoc Fisher's PLSD test). RFU, Relative fluorescence unit.

lines were established from littermates after the last backcross and thus are as genetically similar as possible. Similarly, the protection observed in CD36 nulls cannot be the results of differences in MAP or body temperature, because these variables did not differ between wild-type mice and CD36 nulls. Therefore, the findings of the present study cannot be attributed to confounding effects of genetic background or physiological variables.

After MCA occlusion, the intensity of the ischemic insult is the major determinant of the ensuing tissue damage (Hossmann, 1994). Although the CBF reduction in the ischemic territory did not differ between wild-type and CD36null mice, postischemic CBF was attenuated in the nulls. Postischemic hyperemia is mediated by the release of vasoactive factors from the ischemic brain, including adenosine, $\mathrm{K}^{+}$and $\mathrm{H}^{+}$ions, nitric oxide, as well as ROS, whose production increases at reperfusion (Iadecola, 1998; Marchal et al., 1999). Attenuation in the reactivity of the cerebral circulation to vasoactive stimuli could explain the reduced CBF in CD36 nulls. However, this does not seem to be the case, because the vasodilatatory capacity of the cerebral circulation, as reflected by responses to functional hyperemia, hypercapnia, endotheliumdependent vasodilation, and hypotension, was not attenuated in CD36 nulls. Another possibility is that the production of vasoactive mediators by the ischemic brain is reduced in CD36 nulls. This possibility seems most likely in view of the observation that ROS production was profoundly attenuated in CD36 nulls. ROS are potent vasodilators and contribute to postischemic hyperemia (Iadecola, 1998). However, we doubt that the attenuation in postischemic CBF is the cause of the reduction in injury volume in CD36 nulls. Although the magnitude of CBF increase at reperfusion depends on the duration and the severity of the ischemic insult, the evidence suggests that such hyperemia does not contribute to the injury (Marchal et al., 1999). Therefore, it is unlikely that hemodynamic effects related to ischemia and reperfusion are responsible for the marked protection observed in CD36 nulls.

ROS have long been implicated in the mechanisms of brain damage produced by cerebral ischemia (Kontos, 1985; Traystman et al., 1991; Chan, 2001). Ischemiareperfusion increases ROS production in the affected brain and ROS scavengers protect from the resulting brain injury (Liu et al., 1989; Dugan et al., 1995; Globus et al., 1995; Mackensen et al., 2001). Furthermore, transgenic animals overexpressing the ROS scavenging enzyme superoxide dismutase (SOD) are more resistant to cerebral ischemia (Kinouchi et al., 1991), whereas mice lacking SOD are more susceptible to injury (Kondo et al., 1997). It is, therefore, reasonable to assume that the protection from cerebral ischemia observed in CD36 nulls is, at least in part, attributable to the reduction in postischemic ROS production. It is unlikely that the reduction in ROS production is a consequence rather than a cause of the reduced damage, because in rodent models of cerebral ischemia, the tissue damage is not fully developed at the time that ROS production was greatest $(0-4 \mathrm{~h})$ (Clark et al., 1993). However, the increase in ROS production that occurs $24 \mathrm{~h}$ after MCA occlusion was not attenuated in CD36 nulls, indicating that, in the 

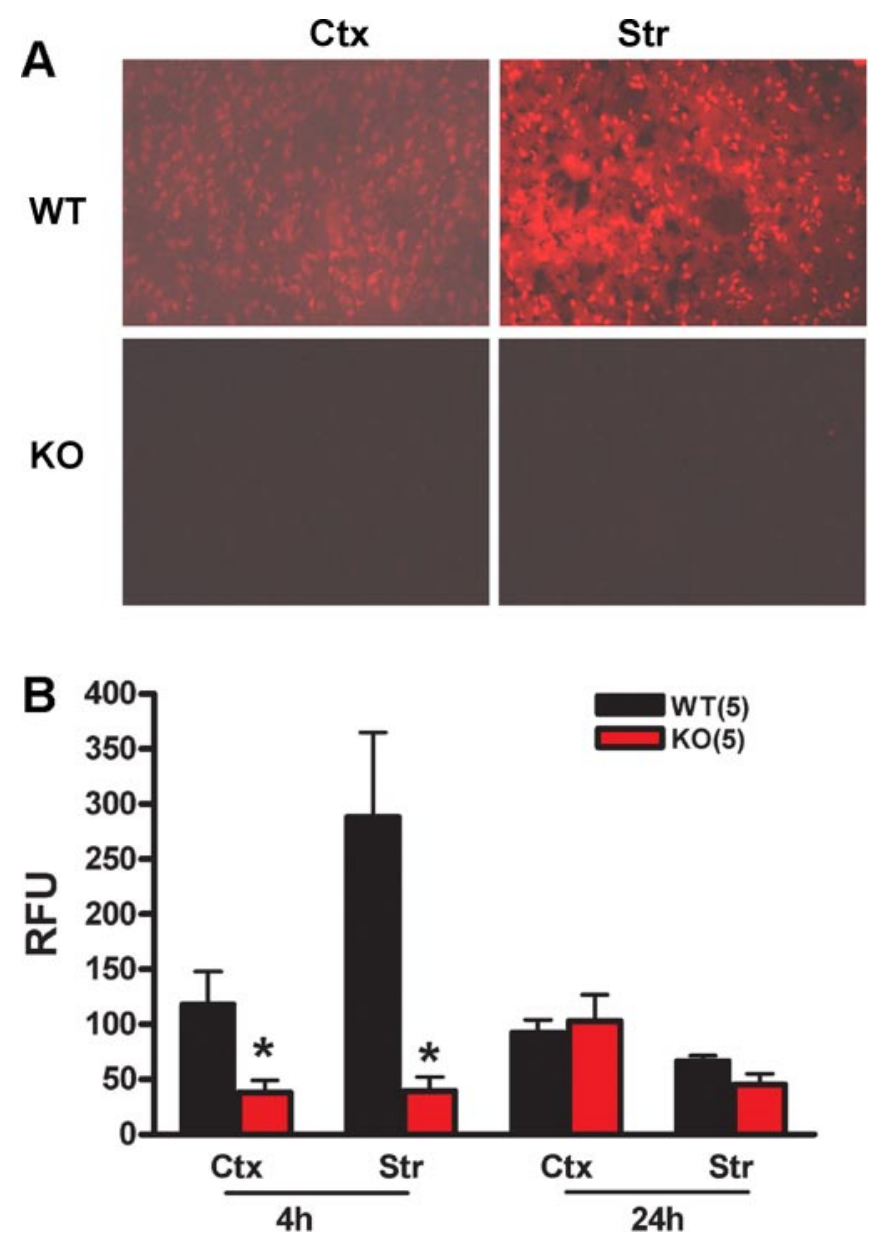

Figure 7. Postischemic ROS production in wild-type (WT) and CD36-null (KO) mice. A, ROS signal is observed $4 \mathrm{~h}$ after MCA occlusion in the cortex (Ctx) and striatum (Str). Photomicrographs were taken at the level of section 3 of Figure $6 A$. B , Semiquantitative analysis of ROS production in cortex and striatum at 4 and $24 \mathrm{~h}$ after ischemia. Error bars indicate $S E .{ }^{*} p<0.05$ from WT.

postischemic brain, ROS are also produced by CD36independent mechanisms. This is not surprising considering that the mechanisms of ROS production in the early phase of cerebral ischemia are likely to be different from those in the late phase (Chan, 2001).

Considering that CD36 is upregulated in cells expressing the microglia/macrophage marker CD11b in the early stages of reperfusion, the data would indicate that these cells contribute to CD36-dependent ROS production. In particular, microglia participate in cerebral ischemic injury, an effect mediated by production of inflammatory mediators and ROS (Giulian, 1997; Schwartz, 2003). However, the specific factors involved in the postischemic ROS production by microglia and macrophages have remained elusive (Giulian, 1997). The present findings provide evidence that $\mathrm{CD} 36$ receptors may be a critical factor in the mechanisms of postischemic ROS production by these cells. Considering that CD36-dependent ROS production occurs early in the postischemic period, it is likely that the increased ROS result from activation of existing CD36 receptors. CD36 activation can then lead to CD36 upregulation via a feedback loop involving PPAR $\gamma$ (peroxisome proliferator-activated receptor- $\gamma$ ) (Nicholson, 2004). In the early stages of ischemia, ROS production is predominantly neuronal (Chan, 2001), but neurons did not exhibit CD36 immunoreactivity. Therefore, one question that remains unanswered is how activation of CD36 in microglia/ macrophages leads to neuronal oxidative stress. Although we cannot rule out low-level neuronal expression of CD36 not detected by immunocytochemistry, it is likely that CD36dependent ROS production in microglia/macrophages triggers oxidative stress in neurons leading to neuronal death. This possibility is supported by studies demonstrating that microglia can induce ROS production and neuronal death in neuron-microglia cocultures (Gao et al., 2003).

The ligands that interact with CD36 during ischemia-reperfusion and the signaling pathways downstream of CD36 remain to be defined. Some CD36 ligands, such as thrombospondin-1, oxidized LDL, $\mathrm{A} \beta$, and long-chain fatty acids, are produced in cerebral ischemic injury (Hayashi et al., 2003; Pilitsis et al., 2003; Uno et al., 2003; Shie et al., 2004). One or more of these factors produced during cerebral ischemia could activate CD36 and initiate subsequent signaling, leading to ROS production. In microglia, CD36 is involved in the production of ROS and inflammatory mediators induced by A $\beta$ (Moore et al., 2002; Bamberger et al., 2003). In these cells, the src kinase family members lyn and fyn, as well as the mitogen-activated protein kinase p44/42 are critical for production of ROS and inflammatory mediators (Moore et al., 2002). However, it remains to be determined whether a similar signaling pathway mediates the deleterious actions of CD36 on the postischemic brain.

CD36 has been implicated in the mechanisms of Alzheimer's disease (AD) (Husemann et al., 2002). CD36 is present in AD brains, but it has not been established whether its expression is unregulated compared with controls (Coraci et al., 2002). Although $\mathrm{A} \beta$, a peptide linked to the pathophysiology of $\mathrm{AD}$, induces CD36-dependent ROS production in microglial cultures (Coraci et al., 2002; Moore et al., 2002; El Khoury et al., 2003), it is unclear whether this receptor has a pathogenic role in the mechanisms of $\mathrm{AD}$. We demonstrated here that CD36 is upregulated in the postischemic brain and that it exerts deleterious effects on the outcome of cerebral ischemia. Therefore, the present findings provide the first demonstration of an involvement of CD36 in brain injury, namely ischemic stroke. In an analogous manner, reduced expression of CD36 may also be implicated in the reduction in cerebral ischemic injury afforded by 3-hydroxy3-methylglutaryl coenzyme inhibitors (statins) (Endres et al., 1998; Yamada et al., 2000; Vaughan et al., 2001). Although this protective effect has been attributed to upregulation of endothelial nitric oxide synthase resulting in a better maintenance of $\mathrm{CBF}$ after MCA occlusion (for review, see Endres et al., 2004), recent data indicate that statins downregulate CD36 expressing in inflammatory cells (Han et al., 2004). Therefore, attenuation of CD36 signaling could be an additional mechanism of the protective effect exerted by statins.

In conclusion, we demonstrated that CD36 is upregulated primarily in microglia/macrophages during cerebral ischemiareperfusion. CD36-null mice are relatively protected from the tissue damage and functional impairment produced by cerebral ischemia. The effect is associated with a reduction in ROS production during the critical phase of the postischemic period when the damage is initiated. The data suggest that signaling mediated through the CD36 scavenger receptor contributes to ischemic brain injury by leading to ROS production during the reperfusion period. The findings establish a novel role of CD36 in brain injury and raise the possibility that this receptor is a potential therapeutic target for the treatment of ischemic stroke. 


\section{References}

Bamberger ME, Harris ME, McDonald DR, Husemann J, Landreth GE (2003) A cell surface receptor complex for fibrillar $\beta$-amyloid mediates microglial activation. J Neurosci 23:2665-2674.

Bindokas VP, Jordan J, Lee CC, Miller RJ (1996) Superoxide production in rat hippocampal neurons: selective imaging with hydroethidine. J Neurosci 16:1324-1336

Bruce AJ, Boling W, Kindy MS, Peschon J, Kraemer PJ, Carpenter MK, Holtsberg FW, Mattson MP (1996) Altered neuronal and microglial responses to excitotoxic and ischemic brain injury in mice lacking TNF receptors. Nat Med 2:788-794.

Carter WO, Narayanan PK, Robinson JP (1994) Intracellular hydrogen peroxide and superoxide anion detection in endothelial cells. J Leukoc Biol 55:253-258.

Chan PH (2001) Reactive oxygen radicals in signaling and damage in the ischemic brain. J Cereb Blood Flow Metab 21:2-14.

Choi DW (1997) Background genes: out of sight, but not out of brain. Trends Neurosci 20:499-500.

Clark RK, Lee EV, Fish CJ, White RF, Price WJ, Jonak ZL, Feuerstein GZ (1993) Development of tissue damage, inflammation and resolution following stroke: an immunohistochemical and quantitative planimetric study. Brain Res Bull 31:565-572.

Coraci IS, Husemann J, Berman JW, Hulette C, Dufour JH, Campanella GK, Luster AD, Silverstein SC, El-Khoury JB (2002) CD36, a class B scavenger receptor, is expressed on microglia in Alzheimer's disease brains and can mediate production of reactive oxygen species in response to $\beta$-amyloid fibrils. Am J Pathol 160:101-112.

Dugan LL, Lin TS, He YY, Hsu CY, Choi DW (1995) Detection of free radicals by microdialysis/spin trapping EPR following focal cerebral ischemia-reperfusion and a cautionary note on the stability of 5,5dimethyl-1-pyrroline $N$-oxide (DMPO). Free Radic Res 23:27-32.

El Khoury JB, Moore KJ, Means TK, Leung J, Terada K, Toft M, Freeman MW, Luster AD (2003) CD36 mediates the innate host response to $\beta$-amyloid. J Exp Med 197:1657-1666.

Endres M, Laufs U, Huang Z, Nakamura T, Huang P, Moskowitz MA, Liao JK (1998) Stroke protection by 3-hydroxy-3-methylglutaryl (HMG)-CoA reductase inhibitors mediated by endothelial nitric oxide synthase. Proc Natl Acad Sci USA 95:8880-8885.

Endres M, Laufs U, Liao JK, Moskowitz MA (2004) Targeting eNOS for stroke protection. Trends Neurosci 27:283-289.

Febbraio M, Abumrad NA, Hajjar DP, Sharma K, Cheng W, Pearce SF, Silverstein RL (1999) A null mutation in murine CD36 reveals an important role in fatty acid and lipoprotein metabolism. J Biol Chem 274:19055-19062.

Febbraio M, Hajjar DP, Silverstein RL (2001) CD36: a class B scavenger receptor involved in angiogenesis, atherosclerosis, inflammation, and lipid metabolism. J Clin Invest 108:785-791.

Finnemann SC, Silverstein RL (2001) Differential roles of CD36 and $\alpha_{\mathrm{v}} \beta_{5}$ integrin in photoreceptor phagocytosis by the retinal pigment epithelium. J Exp Med 194:1289-1298.

Freitag S, Schachner M, Morellini F (2003) Behavioral alterations in mice deficient for the extracellular matrix glycoprotein tenascin-R. Behav Brain Res 145:189-207.

Gao HM, Hong JS, Zhang W, Liu B (2003) Synergistic dopaminergic neurotoxicity of the pesticide rotenone and inflammogen lipopolysaccharide: relevance to the etiology of Parkinson's disease. J Neurosci 23:1228-1236.

Giulian D (1997) Reactive microglia and ischemic injury. In: Primer on cerebrovascular diseases (Weir B, ed), pp 117-124. San Diego: Academic.

Globus MY, Busto R, Lin B, Schnippering H, Ginsberg MD (1995) Detection of free radical activity during transient global ischemia and recirculation: effects of intraischemic brain temperature modulation. J Neurochem 65:1250-1256.

Han J, Zhou X, Yokoyama T, Hajjar DP, Gotto Jr AM, Nicholson AC (2004) Pitavastatin downregulates expression of the macrophage type B scavenger receptor, CD36. Circulation 109:790-796.

Hayashi T, Noshita N, Sugawara T, Chan PH (2003) Temporal profile of angiogenesis and expression of related genes in the brain after ischemia. J Cereb Blood Flow Metab 23:166-180.

Hirano K, Kuwasako T, Nakagawa-Toyama Y, Janabi M, Yamashita S, Matsuzawa Y (2003) Pathophysiology of human genetic CD36 deficiency. Trends Cardiovasc Med 13:136-141.
Hossmann K-A (1994) Viability thresholds and the penumbra of focal ischemia. Ann Neurol 36:557-565.

Husemann J, Loike JD, Anankov R, Febbraio M, Silverstein SC (2002) Scavenger receptors in neurobiology and neuropathology: their role on microglia and other cells of the nervous system. Glia 40:195-205.

Iadecola C (1992) Nitric oxide participates in the cerebrovasodilation elicited from cerebellar fastigial nucleus. Am J Physiol 263:R1156-R1161.

Iadecola C (1998) Cerebral circulatory dysregulation in ischemia. In: Cerebrovascular diseases (Bogousslavsky J, ed), pp 319-332. Cambridge, MA: Blackwell Science.

Iadecola C, Salkowski CA, Zhang F, Aber T, Nagayama M, Vogel SN, Ross ME (1999a) The transcription factor interferon regulatory factor 1 is expressed after cerebral ischemia and contributes to ischemic brain injury. J Exp Med 189:719-727.

Iadecola C, Zhang F, Niwa K, Eckman C, Turner SK, Fischer E, Younkin S, Borchelt DR, Hsiao KK, Carlson GA (1999b) SOD1 rescues cerebral endothelial dysfunction in mice overexpressing amyloid precursor protein. Nat Neurosci 2:157-161.

Iadecola C, Niwa K, Nogawa S, Zhao X, Nagayama M, Araki E, Morham S, Ross ME (2001) Reduced susceptibility to ischemic brain injury and NMDA-mediated neurotoxicity in cyclooxygenase-2 deficient mice. Proc Natl Acad Sci USA 98:1294-1299.

Iadecola C, Cho S, Feuerstein GZ, Hallenbeck J (2004) Cerebral ischemia and inflammation. In: Stroke: pathophysiology, diagnosis, and management (Wolf P, ed), pp 883-894. New York: Churchill Livingstone.

Ikegami S, Harada A, Hirokawa N (2000) Muscle weakness, hyperactivity, and impairment in fear conditioning in tau-deficient mice. Neurosci Lett 279:129-132.

Kinouchi H, Epstein CJ, Mizui T, Carlson E, Chen SF, Chan PH (1991) Attenuation of focal cerebral ischemic injury in transgenic mice overexpressing CuZn superoxide dismutase. Proc Natl Acad Sci USA $88: 11158-11162$

Kondo T, Reaume AG, Huang T-T, Carlson E, Murakami K, Chen SF, Hoffman EK, Scott RW, Epstein CJ, Chan PH (1997) Reduction of CuZnsuperoxide dismutase activity exacerbates neuronal cell injury and edema formation after transient focal cerebral ischemia. J Neurosci 17:4180-4189.

Kontos HA (1985) Oxygen radicals in cerebral vascular injury. Circ Res 57:508-516.

Lin T-N, He YY, Wu G, Khan M, Hsu CY (1993) Effect of brain edema on infarct volume in a focal cerebral ischemia model in rats. Stroke 24:117-121.

Liu TH, Beckman JS, Freeman BA, Hogan EL, Hsu CY (1989) Polyethylene glycol-conjugated superoxide dismutase and catalase reduce ischemic brain injury. Am J Physiol H589-H593.

Lo EH, Dalkara T, Moskowitz MA (2003) Mechanisms, challenges and opportunities in stroke. Nat Rev Neurosci 4:399-415.

Mackensen GB, Patel M, Sheng H, Calvi CL, Batinic-Haberle I, Day BJ, Liang LP, Fridovich I, Crapo JD, Pearlstein RD, Warner DS (2001) Neuroprotection from delayed postischemic administration of a metalloporphyrin catalytic antioxidant. J Neurosci 21:4582-4592.

Manabe Y, Anrather J, Kawano T, Niwa K, Zhou P, Ross ME, Iadecola C (2004) Prostanoids, not reactive oxygen species, mediate COX-2dependent neurotoxicity. Ann Neurol 55:668-675.

Marchal G, Young AR, Baron JC (1999) Early postischemic hyperperfusion: pathophysiologic insights from positron emission tomography. J Cereb Blood Flow Metab 19:467-482.

Medeiros LA, Khan T, El Khoury JB, Pham CL, Hatters DM, Howlett GJ, Lopez R, O’Brien KD, Moore KJ (2004) Fibrillar amyloid protein present in atheroma activates CD36 signal transduction. J Biol Chem 279:10643-10648.

Moore KJ, El Khoury J, Medeiros LA, Terada K, Geula C, Luster AD, Freeman MW (2002) A CD36-initiated signaling cascade mediates inflammatory effects of $\beta$-amyloid. J Biol Chem 277:47373-47379.

Murakami K, Kondo T, Kawase M, Li Y, Sato S, Chen SF, Chan PH (1998) Mitochondrial susceptibility to oxidative stress exacerbates cerebral infarction that follows permanent focal cerebral ischemia in mutant mice with manganese superoxide dismutase deficiency. J Neurosci 18:205-213.

Nicholson AC (2004) Expression of CD36 in macrophages and atherosclerosis: the role of lipid regulation of PPAR $\gamma$ signaling. Trends Cardiovasc Med 14:8-12

Nihashi T, Inao S, Kajita Y, Kawai T, Sugimoto T, Niwa M, Kabeya R, Hata N, 
Hayashi S, Yoshida J (2001) Expression and distribution of $\beta$-amyloid precursor protein and $\beta$-amyloid peptide in reactive astrocytes after transient middle cerebral artery occlusion. Acta Neurochir (Wien) 143:287-295.

Niwa K, Younkin L, Ebeling C, Turner SK, Westaway D, Younkin S, Ashe KH, Carlson GA, Iadecola C (2000) A $\beta 1-40$-related reduction in functional hyperemia in mouse neocortex during somatosensory activation. Proc Natl Acad Sci USA 97:9735-9740.

Niwa K, Haensel C, Ross ME, Iadecola C (2001) Cyclooxygenase-1 participates in selected vasodilator responses of the cerebral circulation. Circ Res 88:600-608.

Niwa K, Kazama K, Younkin L, Younkin SG, Carlson GA, Iadecola C (2002) Cerebrovascular autoregulation is profoundly impaired in mice overexpressing amyloid precursor protein. Am J Physiol 283:H315-H323.

Nogawa S, Zhang F, Ross ME, Iadecola C (1997) Cyclooxygenase-2 gene expression in neurons contributes to ischemic brain damage. J Neurosci 17:2746-2755.

Park E-M, Cho S, Frys K, Racchumi G, Zhou P, Anrather J, Iadecola C (2004) Interaction between inducible nitric oxide synthase and poly(ADPribose) polymerase in focal ischemic brain injury. Stroke 35:2896-2901.

Paulson OB, Strandgaard S, Edvinsson L (1990) Cerebral autoregulation. Cerebrovasc Brain Metab Rev 2:162-192.

Pilitsis JG, Coplin WM, O'Regan MH, Wellwood JM, Diaz FG, Fairfax MR, Michael DB, Phillis JW (2003) Measurement of free fatty acids in cerebrospinal fluid from patients with hemorrhagic and ischemic stroke. Brain Res 985:198-201.

Rothe G, Valet G (1990) Flow cytometric analysis of respiratory burst activ- ity in phagocytes with hydroethidine and $2^{\prime}, 7^{\prime}$-dichlorofluorescin. J Leukoc Biol 47:440-448.

Schwartz M (2003) Macrophages and microglia in central nervous system injury: are they helpful or harmful? J Cereb Blood Flow Metab 23:385-394.

Shie FS, Neely MD, Maezawa I, Wu H, Olson SJ, Jurgens G, Montine KS, Montine TJ (2004) Oxidized low-density lipoprotein is present in astrocytes surrounding cerebral infarcts and stimulates astrocyte interleukin-6 secretion. Am J Pathol 164:1173-1181.

Traystman RJ, Kirsch JR, Koehler RC (1991) Oxygen radical mechanisms of brain injury following ischemia and reperfusion. J Appl Physiol 71:1185-1195.

Uno M, Kitazato KT, Nishi K, Itabe H, Nagahiro S (2003) Raised plasma oxidised LDL in acute cerebral infarction. J Neurol Neurosurg Psychiatry 74:312-316.

Vaughan CJ, Delanty N, Basson CT (2001) Statin therapy and stroke prevention. Curr Opin Cardiol 16:219-224.

Yamada M, Huang Z, Dalkara T, Endres M, Laufs U, Waeber C, Huang PL, Liao JK, Moskowitz MA (2000) Endothelial nitric oxide synthasedependent cerebral blood flow augmentation by L-arginine after chronic statin treatment. J Cereb Blood Flow Metab 20:709-717.

Yrjanheikki J, Tikka T, Keinanen R, Goldsteins G, Chan PH, Koistinaho J (1999) A tetracycline derivative, minocycline, reduces inflammation and protects against focal cerebral ischemia with a wide therapeutic window. Proc Natl Acad Sci USA 96:13496-13500. 